\section{Medical Practices Committee}

\author{
W B WHOWELL
}

Though it affects all general practitioners, the Medical Practices Committee and its workings are little understood. It was set up to implemen the principle of the National Health Service that there should be adequate numbers of family doctors throughout the country, and the way it classifies an area may affect considerably the general practitioners practising there. In areas considered to be overdoctored, for example, it may prevent doctors taking a partner or setting up in practice, while doctors in severely underdoctored areas may be entitled to substantial financial allowances.

The MPC's principal function is to control the distribution of GPs in England and Wales (there is a separate MPC for Scotland, and Northern Ireland has different arrangements). It does this by considering all applications for inclusion on the medical lists kept by family practitioner committees and by reviewing the need to fill practice vacancies. Its actual controls are negative ones: the MPC cannot tell doctors where to go, but it can tell them where they may not practise.

The MPC also acts as an appeal body on decisions by FPCs to refuse the employmen of assistants or allow the use of surgeries that have been used by another GP. Doctors may also apply to the MPC for a certificate to show that partnership arrangements do not include the sale of goodwill (which is forbidden in the NHS).

\section{Classification}

To determine which areas have enough doctors and which need more and therefore whether new doctors will be admitted or not, the MPC classifies all practice areas into one of four categories. Each FPC area is divided into several practice areas, which usually consist of parts of local government districts, groups of parishes or wards, or parliamentary divisions. So far as possible rural and urban areas are segregated, and urban areas should have no more than $30-40$ doctors practising in them. In rural areas the size depends more on local circumstances. MPC policy is to agree these area boundaries with the local FPC, though it does have the right to determine the areas itself. The areas are kept up to date through the FPCs' yearly returns, which show where their doctors are and the size of their lists, and these reports are updated every time a doctor retires, dies, or joins the medical list. Classifications are therefore automatically reviewed whenever a doctor leaves or enters the area. Doctors practising in the area may also apply through their FPC to have the boundaries redrawn if they consider that they practise in a pocket that is different from the area as a whole.

Classifications are based on the average number of patients registered with the GPs in each practice area, taking account of forthcoming resignations and admissions to the list

Medical Practices Committee, London WC1 W B WHOWELL, MB, FRCGP, chairman plus the addition of one more doctor. The addition of this nominal extra doctor provides for stability of classifications.

\begin{tabular}{ll}
\hline Average list & Classification \\
\hline$\geqslant 2501$ & Designated \\
$2101-2500$ & Open \\
$1701-2100$ & Intermediate \\
$\leqslant 1700$ & Restricted \\
\hline
\end{tabular}

Not all areas with an average list size of more than 2500 are in fact classified as designated: where the actual average list is 2501 or more this average less 2500 is multiplied by the number of doctors in the area to give the "overspill." When the overspill is 2500 or more the area is classified as designated. Once designated an area keeps this classification until the overspill falls below 1000 . The use of the overspill gives stability to the designated classification; without it some areas would be changing from designated to open and back again every year.

In October 1975 the MPC changed the criteria by increasing the lower limits for underdoctored parts of England and Wales. The lower limit of open areas was raised from 2101 to 2201 , so bringing more practices into the intermediate category. By early 1981 this change, together with increases in the number of new entrants to general practice, had reduced the number of designated and open areas. On the other hand, the MPC's control over admissions to the medical list had been extended by the large increase in the number of intermediate areas, whose lower limit was then 1801. The MPC therefore decided from 1 May 1981 to reduce by 100 the lower limits for classifying areas as open and intermediate, resulting in the bands shown above.

\section{Assessing the average list size}

In assessing the average list size the MPC does not simply count all the practising GPs and their lists. Some elderly and part-time doctors are excluded, some are counted as half, and the figures are adjusted to take account of inflation (see below). If a doctor is excluded from the count then his list is also excluded from the total number of patients in the area, but if he is counted as half then his whole list is included.

Earlier this year the study group on primary care in London recommended that all GPs open areas in an attempt to help the chronically

with lists of 700 to 1250 should be counted as half for classification purposes. The MPC does not accept the need for this change and is content with the revised arrangements it has recently introduced (to exclude all singlehanded principals aged 65 and over with lists of 1000 or less, and to count as half singlehanded principals over 65 with lists of 1001 to 1500).

The MPC considers several factors in constructing a notional list for each principaland not just the average list size. One of the most important is inflation. Lists become inflated because patients emigrate, die, move, or change doctors. Inflation is calculated by comparing the number of people registered with GPs and the estimated civilian population. Nationally lists are inflated by an average of $5.8 \%$. In an area where inflation exceeds this by more than $1 \%$ those GPs' actual lists are reduced by the appropriate percentage; an individual GP's notional list may rise again, however, if he has rural practice payments or many temporary residents. Nevertheless, high inflation tends to produce more intermediate and restricted areas.

The four types of areas may be seen as two pairs. Restricted and intermediate areas are well and adequately doctored respectively, and the MPC can refuse to admit doctors wanting to practise in these areas; it does not, however, necessarily reject all applications. Open and designated areas, on the other hand, are considered to be underdoctored and the MPC cannot stop appropriately qualified doctors practising as principals in them. Indeed, the main purpose of a designated classification is to attract more doctors to an area by providing initial practice allowances for newcomers. In designated and open areas GPs tend to have larger lists than the average in England and Wales of 2238. Requests to fill vacancies and applications to start a new practice or join an existing one are therefore usually granted without question and processed formally at the MPC's weekly meetings.

Applications to join the list in a restricted or intermediate area are not automatically rejected. The MPC uses the classifications as a starting point but considers each application individually. The FPC has to provide all local details that might affect the issue, including not only the doctor's age and list but also similar information for nearby practices and for the practice area as a whole, adjusted for inflation. The doctor's outside professional commitments, especially any hospital appointments, are noted.

The lists of doctors in the practice are analysed-for example, to take into account the number of temporary residents treated or the extent to which rural doctors are credited with rural practice units-to indicate the doctor's work load. Other important factors are the number of elderly patients on the doctor's list and, where appropriate, the

\begin{tabular}{lll}
\hline Doctors counted as 1 principal & Doctors counted as $\frac{1}{2}$ principal & Doctors excluded \\
\hline $\begin{array}{c}\text { Principals in partnership receiving } \\
\geqslant 74 \% \text { of basic practice allowance }\end{array}$ & $\begin{array}{c}\text { Principals receiving } 25-74 \% \\
\text { of BPA }\end{array}$ & Principals receiving $\leqslant 25 \%$ of BPA \\
$\begin{array}{c}\text { Singlehanded principals of } \leqslant 65 \\
\text { years with: } \\
\text { lists of } \begin{array}{l}\text { Singlehanded principals of } \\
\text { lists of } \leqslant 700 \text { in rural areas } \\
\text { or if being built up }\end{array}\end{array}$ & $\begin{array}{c}\text { Singlehanded principals with lists } \\
\text { of } \leqslant 700\end{array}$ \\
$\begin{array}{c}\text { Full-time assistants with view } \\
1001-1500\end{array}$ & Full-time assistant without view lists of & $\begin{array}{c}\text { Singlehanded principals of } \\
\geqslant 65 \text { with lists under } 1000\end{array}$ \\
& & $\begin{array}{c}\text { Limited list principals } \\
\text { Principals providing only maternity } \\
\text { services }\end{array}$ \\
Trainees and locums
\end{tabular}


number of patients for whom a practice dispenses. Local circumstances such as trafficcongested roads may also be taken into account.

The MPC tries hard to ensure that all cases are examined fairly and in detail. But this depends partly on the information it is given The committee cannot, for example, be expected to know without being told that the reason a doctor is seeking a partner is because he wants to reduce his own work load after a coronary. The FPC has a duty to supply what information it knows, but individual doctors may also provide information to the MPC.

\section{Replacing a doctor}

When a vacancy occurs in a partnership the MPC is responsible for appointing another to fill the vacancy. As soon as the FPC is told of a death or resignation it consults the local medical committee and sends a report to the MPC on the need for a replacement. If the area is intermediate or restricted the FPC may recommend that no replacement is needed. If the remaining partners disagree and want to appoint a successor they may make their own representations to the MPC, so that their case can be considered in parallel with the FPC's.

When the practice commitments do not seem to justify a normal replacement but would represent a heavy load for the remaining partners the MPC will sometimes allow a new partner on condition that the doctor concerned is tied to the area. For example a woman doctor may have family commitments that keep her in the area and would make it impossible for her to practise in a less well doctored area. Similar considerations may apply to a male doctor as well. In other cases the MPC may allow a replacement partner but make it clear that the practice would not necessarily be regarded as always needing that many doctors. When the MPC rejects an application for a replacement partner it will allow the remaining partners to succeed to the list of the departing partner.

Once the MPC has given approval for a vacancy to be filled it will normally allow the remaining partners to choose a new partner.

The MPC is ultimately responsible for appointing a doctor to a singlehanded vacancy but it delegates the initial consideration of applicants to the FPC. The FPC advertises the vacancy, shortlists candidates, interviews them, and sends all the applications to the MPC with its recommendations on whom to appoint. If the singlehanded vacancy occurs in a health centre one of the doctors there is usually invited to attend the FPC interview as an observer because it is in no one's interests to appoint a doctor who may not be compatible with others working at the centre. Occasionally the MPC will not accept the FPC's recommendation. It will then invite a further shortlist of candidates for interview at the MPC's offices in London. The FPC will also be asked to send representatives, including a representative of the $\mathrm{LMC}$, to attend the session.

If a singlehanded vacancy occurs in a restricted or intermediate area the FPC has to ask the MPC's permission to advertise the vacancy. The MPC may instead decide to disperse the practice or stipulate that only doctors on the local list can apply.

The MPC's policy is to give weight to length of experience in general practice in the UK, especially in the sort of practice that has become vacant. For example, it might be a

\section{Constitution}

The MPC is an autonomous body with a chairman and eight other members appointed by the Secretary of State after consultation with the General Medical Services Committee. The chairman and six other members are GPs, and at least five of the six must be in active practice. Usually two are from London, one from Wales, and the rest from other parts of England. One of the two lay members is usually legally qualified and the other is usually appointed after consultation with the Society of Family Practitioner Committees. Each member serves for three years, though the term is renewable. The committee is supported by a staff of civil servants seconded from the DHSS. Present members are: Dr W B Whowell (chairman), Dr R A Arthur, Dr F W Blacklay, Dr G W Clark, Dr G Cormack, Mr K F G Day, Dr H J Eastes, Dr E Ann Thomson, and Mrs J Thomas.

dispensing practice or there may be hospital sessions on offer. This policy and the MPC's reluctance to appoint to singlehanded practices young doctors who have only just completed vocational training have been criticised. But the committee considers that while inexperienced doctors may fill vacancies where there is a partner to guide them they have less claim to take sole charge of a singlehanded practice. Until recently candidates with less than two years' experience as a principal would have stood little chance of gaining a singlehanded vacancy, but the MPC has now relaxed this stipulation.

The MPC does not exclude candidates on the grounds of age, and being over 50 years is no bar. Although the length and type of experience are important, so is potential, and the committee also takes account of the candidate's administrative skills, ability to use ancillary help, higher qualifications useful in general practice, and personality.

In areas where the average list is large the MPC is reluctant to appoint a local doctor to a vacancy unless he makes a joint application with a new partner from outside. For a small practice in an attractive area the MPC may consider seriously older practitioners seeking less demanding responsibilities.

The MPC advises FPCs not to tell their nominated candidate that he has been selected. Once the MPC has selected the doctor he will be told, but even then he should not regard that appointment as certain, for unsuccessful candidates may appeal, in which case the final decision rests with the Secretary of State. Finally, the selected candidate has to show the FPC that he has made acceptable arrangements for accommodating and staffing the vacant practice.

Some singlehanded practitioners who want to appoint their own successors try to get round the rules by taking a partner and retiring shortly afterwards, in the hope that the new partner will be able to take over the practice. The MPC will not normally accept one partner as successor to another who has died or resigned if the partners have been together for less than one year. There are, of course, exceptions. A genuine partnership might, for example, be ended by the sudden illness or death of the original partner or the partners may be related or the appointment delayed for a good reason.

\section{Appeals and sale of goodwill}

Any doctor who applies to be admitted to the medical list or applies for a vacancy and is unsuccessful may appeal to the Secretary of State. A doctor may also appeal if his application has been successful but the MPC has laid down conditions. Appeals must be lodged within seven days of receiving notification of the MPC's decision and should contain a concise statement of the grounds for the appeal. Usually the matter will be dealt with from the written evidence, but the Secretary of State may appoint a panel to hold an oral hearing.

The MPC itself is an appeal body for cases where the FPC has refused to allow a doctor to employ an assistant or to use premises that have been used by another doctor as described in paras 27 and 28 of the Terms of Service. If a doctor appeals against an FPC decision on any of these points he should make a detailed case in writing to the MPC. If necessary the MPC will hold an oral hearing.

Before 1948 there was a "free market" in medical practices, and the "goodwill" of a practice often accounted for a large part of the purchase price. In setting up the MPC to ensure an even distribution of GPs the NHS Act also outlawed the sale of goodwill in NHS practices. A sale of goodwill is assumed if the selling or letting price of the premises is much greater than that which "might reasonably have been expected if the premises had not previously been used for a medical practice." A GP can ask the MPC for a certificate to show that a proposed transaction does not include the sale of goodwill. He should also enclose the terms of his partnership when applying. The MPC deals with about three or four requests a month and now rarely sees a case of possible sale of goodwill.

\section{A flexible approach}

The MPC's task is hardly a popular one, and it has long been criticised by those who are prevented from setting up their practices at will. Though the committee does a job that has been imposed by successive Governments since the start of the NHS, the task is done independently of the DHSS.

The hallmark of the committee's approach to individual cases is flexibility. The starting point in any assessment of distribution of GPs is the average list size, but numbers are just the start and the MPC will bend the rules in every direction without ever breaking them.

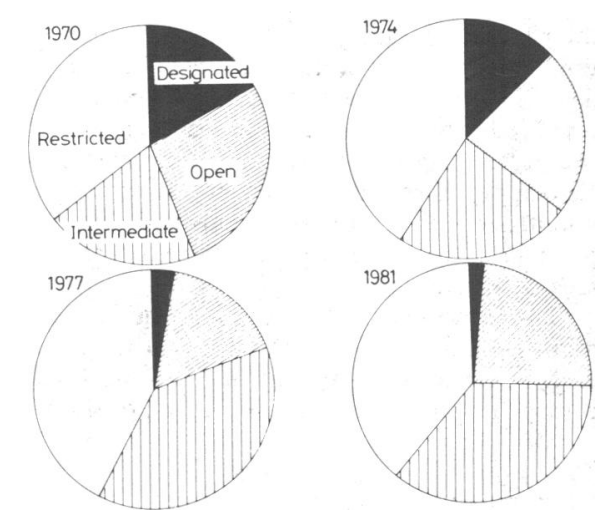

Changes in classification of practice areas in England and Wales 1970-81. 